\title{
SURVEY OF RESIDENT'S KNOWLEDGE AND ATTITUDE ABOUT PREOPERATIVE EVALUATION
}

\author{
Susanta Sarkar1, Mohanchandra Mandal2, Subhrajyoti Chattopadhyay33, Anirban Karmakar4, Biswanath Sarkar5, Suchitra Pal6, \\ Sekhar Ranjan Basu ${ }^{7}$
}

${ }^{1}$ Associate Professor, Department of Anaesthesiology, North Bengal Medical College, Sushrutanagar, Darjeeling, West Bengal, India. 2 Associate Professor, Department of Anaesthesiology, North Bengal Medical College, Sushrutanagar, Darjeeling, West Bengal, India. ${ }_{3}^{3}$ Assistant Professor, Department of Anaesthesiology, North Bengal Medical College, Sushrutanagar, Darjeeling, West Bengal, India. ${ }_{4}^{4}$ Postgraduate Trainee, Department of Anaesthesiology, North Bengal Medical College, Sushrutanagar, Darjeeling, West Bengal, India. ${ }_{5}^{5}$ Postgraduate Trainee, Department of Anaesthesiology, North Bengal Medical College, Sushrutanagar, Darjeeling, West Bengal, India. ${ }^{6}$ Nursing Sister, M. Sc. Nursing (Psychiatry), Central Hospital, SE Railway, Garden Reach, Kolkata, West Bengal. 7 Professor and HOD, Department of Anaesthesiology, North Bengal Medical College, Sushrutanagar, Darjeeling, West Bengal, India.

ABSTRACT
BACKGROUND
In health care system, there is a growing emphasis on the reduction of heath care costs while assuring a high-quality care and
improved outcomes. At the time of pre-anaesthetic evaluation often a battery of tests, not fully justified, is advised by the residents
as well as anaesthesiologists. The present study is aimed to assess the residents' existing knowledge and attitude regarding
preanaesthetic evaluation.

\section{MATERIALS AND METHODS}

The present cross-sectional, observational paper-based questionnaire survey (comprised of 10 questions) was conducted upon 76 residents of surgical sub-specialities of a tertiary care centre to evaluate the domain of knowledge regarding preoperative investigations, risk assessment for anaesthesia, general guideline of preoperative medication for coexisting diseases and fluid therapy during fasting condition.

\section{RESULTS}

Regarding the knowledge of preoperative investigations, only $1.3-9.2 \%$ of all residents choose the correct options. Majority of residents (Around 71 - 93\%) favoured to prescribe a battery of investigations for preoperative anaesthesia fitness. In response to questions to evaluate the knowledge of risk assessment for anaesthesia, the proportion of residents opted correct response ranges from 61 -90\%. Also inconsistent responses were observed regarding continuation of preoperative drugs for two co-existing diseases.

\section{CONCLUSION}

Residents bear poor knowledge regarding preanaesthesia evaluation as is evident from gross incorrect responses, especially considering the baseline standard of questionnaire. Further enrichment of residents' knowledge is desired, which can be accomplished through educational interventions and frequent updating. This might help in proper utilisation of existing resources, thereby increasing surgical turnover and resultant increased patient satisfaction.

\section{KEYWORDS}

Anaesthesia, Attitude, Knowledge, Physical Examination, Preoperative Evaluation, Resident, Surveys and Questionnaires.

HOW TO CITE THIS ARTICLE: Sarkar S, Mandal M, Chattopadhyay S, et al. Survey of resident's knowledge and attitude about preoperative evaluation. J. Evolution Med. Dent. Sci. 2016;5(96):7076-7080, DOI: 10. 14260/jemds/2016/1601

\section{BACKGROUND}

The role of anaesthesia care in the healthcare system has revolutionised with its expansion from intraoperative to a perioperative field. There is a growing emphasis on the reduction of heath care costs while maintaining a high-quality care and assuring improved medical outcomes. ${ }^{1}$ This has created professional opportunities and intellectual challenges for the anaesthesiologists. ${ }^{2}$

Financial or Other, Competing Interest: None.

Submission 26-10-2016, Peer Review 17-11-2016,

Acceptance 25-11-2016, Published 01-12-2016.

Corresponding Author:

Dr. Susanta Sarkar,

Flat No. B/2/2,

Himalaya Residency,

Babupara, Siliguri,

West Bengal, India.

E-mail: susantaanesth@yahoo.in

DOI: $10.14260 / \mathrm{jemds} / 2016 / 1601$
Preanaesthetic evaluation is a basic element in anaesthesia care. At the time of Preanaesthetic Check-Up (PAC), patients require preoperative diagnostic and laboratory studies that are consistent with their medical history, clinical examination, the proposed surgical procedure and potential for perioperative complications. ${ }^{3}$ During this preoperative assessment and preparation, often a battery of tests is advised by the residents as well as anaesthesiologist which cannot be justified. It is costly and clinically inappropriate. Any incidental findings puts compulsion for further evaluation to avoid medicolegal issues and it has little implication in modifying the final outcome for the patient other than undue delay in surgery, harassment of patient and family member, and burden on proper utilisation of resources.

Anaesthesiologist's involvement in assessing and optimising the surgical patients in a preoperative clinic has shown to curtail unnecessary testing and thereby reducing the related costs, operating room delays and cancellations. This translates into improved patient satisfaction.4,5 
Continued improvement in preoperative assessment rely on educating anaesthesiologists in the skills of physical diagnosis and patient assessment, personnel management and conducting outcome-based research. ${ }^{6}$

There is a clear note in the guidelines that routine investigations are not at all needed in every patient. 3,7 The present study is aimed to assess the residents' existing knowledge and attitude regarding anaesthesia fitness in this geographical area. This survey was done among the interns, house-staffs and postgraduate trainees in the PAC clinic and wards of surgical sub-specialities. This study may help in making modification in residents' knowledge through educational intervention in taking decision regarding basic minimal investigations, preoperative risk assessment and preparation for anaesthesia to provide cost effective health care and best utilisation of the existing resources.

\section{MATERIALS AND METHODS}

After approval of Institute's Ethics Committee, the present cross-sectional, observational paper-based questionnaire survey was conducted over a span of six months from October 2015 to March 2016 in the PAC Clinic of Department of Anaesthesiology as well as in different wards related to surgical sub-specialities of a tertiary care centre (Government Medical College). The participants were interns, house-staffs and post-graduate trainees of different surgical subspecialities (General Surgery, Obstetrics and Gynaecology, E.N.T. and Orthopaedics) and Anaesthesiology. Residents' knowledge was evaluated by paper-based questionnaires, (Annexure 1) comprised of 10 questions of MCQ type to cover the domains of knowledge on preoperative investigations (Question no. 1, 2, 3, 4), risk assessment for anaesthesia (Question no. 5, 6, 7) as well as general guideline of preoperative medication for coexisting diseases and fluid therapy during fasting condition (Question no. 8, 9, 10). Participants were asked to answer all questions according to their knowledge without help of any gadgets. The validity of content of questionnaires was verified by three experts in the field of anaesthesiology. The questionnaire was supplied to the participants in the format mentioned in Annexure-1, but without keys. Data collected from all residents were entered in the Microsoft Excel sheet. The number of participants, their percentages, the mode of option selected for each question was calculated.

\section{RESULTS}

A total of 76 residents were approached for their participation in this survey. All residents returned with their responses. It consists of responses from 26 interns, 24 from residents of one year experience ( 13 house-staffs and 11 postgraduate trainees of first year) and 26 from residents of more than one year's experience (Postgraduates of $2^{\text {nd }}$ and $3^{\text {rd }}$ year). Considering the experience of one year post-internship, the house-staffs and postgraduate trainees of first year were conglomerated together. The participants were from different surgical subspecialties (i.e. General Surgery, Orthopaedics, Gynaecology and Obstetrics, ENT) and from Department of Anaesthesiology. The year-wise sub-classification from different discipline was not possible considering the small numbers of residents involved. Majority of participants were male (around 84\%). The demographic parameters and descriptive characteristics of residents are shown in Table 1.

In response to question no. 1 and 2 to assess the knowledge of preoperative investigations, only $9.2 \%$ (7 of 76) and $1.3 \%$ (01 of 76) of all residents choose the correct options. Majority of residents (around 71 - 93\%) favoured to prescribe a battery of investigations for preoperative anaesthesia fitness. Only 38\% (29 of 76) and 21\% (16 of 76) residents favoured necessary investigations after assessing the functional status of co-morbid conditions when assessed with question no. 3 and 4, respectively. Here, interns responded better (Correct answer in 62\%) than the overall scores achieved (Table 2).

In response to question no. 5, 6 and 7 to evaluate the knowledge of risk assessment for anaesthesia, the correct responses observed among $61 \%, 76 \%$ and $90 \%$ of residents, respectively. Here, interns scored comparatively poorer especially with question 5 and 6 . While assessing the knowledge on continuation of drug therapy in patients with coexisting diseases, $90 \%$ (68 of 76) and 33\% (25 of 76) residents had correct idea in response to question no. 8 and 9 respectively (Table 2).

Regarding preoperative fluid therapy during fasting condition as evaluated by question no. 10, about $88 \%$ (67 of 76) residents opted with correct response (Table 2).

\begin{tabular}{|c|c|c|c|c|c|c|}
\hline \multirow{2}{*}{ Parameter } & \multicolumn{5}{|c|}{ Disciplines Covered } & \multirow{2}{*}{ Total $n=76$} \\
\hline & Surgery & G \& 0 & Orthopaedics & ENT & Anaesthesiology & \\
\hline Interns & - & - & - & - & - & $26(34 \%)$ \\
\hline $\begin{array}{l}\text { House Staff \& } \\
1^{\text {st }} \text { year PGTs }\end{array}$ & 9 & 6 & 4 & 2 & 3 & $24(32 \%)$ \\
\hline $\begin{array}{c}2^{\text {nd }} \text { and } 3^{\text {rd }} \text { year } \\
\text { PGTs }\end{array}$ & 13 & 5 & 4 & 2 & 2 & $26(34 \%)$ \\
\hline \multicolumn{7}{|c|}{ Table 1. Discipline-Wise Distribution of Number of Residents } \\
\hline
\end{tabular}




\begin{tabular}{|c|c|c|c|c|c|c|}
\hline $\begin{array}{l}\text { Qn. } \\
\text { No. }\end{array}$ & $\begin{array}{l}\text { Interns } \\
(n=26)\end{array}$ & $\begin{array}{c}\text { HS and 1st yr. PGT } \\
(n=24)\end{array}$ & $\begin{array}{c}2^{\text {nd }} \text { and } 3 \text { rd yr. PGT } \\
(n=26)\end{array}$ & $\begin{array}{c}\text { Total } \\
(n=76)\end{array}$ & $\begin{array}{l}\text { Mode of Options } \\
\text { Chosen (\%) }\end{array}$ & $\begin{array}{c}\text { Keys } \\
\text { (Right Answer) }\end{array}$ \\
\hline 1 & 0 & 0 & $7(27 \%)$ & $7(9.2 \%)$ & $\mathrm{B}(71)$ & $\mathrm{D}$ \\
\hline 2 & 0 & $1(4 \%)$ & 0 & $1(1.3 \%)$ & $A(93)$ & $\mathrm{B}$ \\
\hline 3 & $16(62 \%)$ & $5(21 \%)$ & $8(31 \%)$ & $29(38 \%)$ & A (62) & $\mathrm{B}$ \\
\hline 4 & $7(27 \%)$ & $2(8 \%)$ & $7(27 \%)$ & $16(21 \%)$ & $\mathrm{A}(80)$ & B \\
\hline 5 & $13(50 \%)$ & $15(63 \%)$ & $18(69 \%)$ & $46(61 \%)$ & $\mathrm{C}(62)$ & $\mathrm{C}$ \\
\hline 6 & $15(58 \%)$ & $20(83 \%)$ & $23(89 \%)$ & $58(76 \%)$ & $\mathrm{C}(75)$ & $\mathrm{C}$ \\
\hline 7 & $23(89 \%)$ & $22(88 \%)$ & $23(89 \%)$ & $68(90 \%)$ & $A(90)$ & $\mathrm{A}$ \\
\hline 8 & $21(81 \%)$ & $22(92 \%)$ & $25(96 \%)$ & $68(90 \%)$ & $A(90)$ & $\mathrm{A}$ \\
\hline 9 & $8(31 \%)$ & $5(21 \%)$ & $12(46 \%)$ & $25(33 \%)$ & $\mathrm{C}(33)$ & $\mathrm{C}$ \\
\hline 10 & $22(85 \%)$ & $21(84 \%)$ & $24(92 \%)$ & $67(88 \%)$ & $A(88)$ & $\mathrm{A}$ \\
\hline \multicolumn{7}{|c|}{ Table 2. Pattern of Residents' Response } \\
\hline \multicolumn{7}{|c|}{$\begin{array}{l}\text { Data expressed as number of correct respondents (\%) and the options chosen by the majority (\%). Most of the } \\
\text { values are expressed in round figures by omitting the values after decimal, considering the less } \\
\text { practical implication of such fractions and also for ease of understanding }\end{array}$} \\
\hline
\end{tabular}

\section{DISCUSSION}

Preanaesthetic evaluation is done during preanaesthetic check-up to gather information about the patient and to formulate an anaesthetic plan for conducting smooth and safe anaesthesia during surgery with an insight to avoid perioperative morbidity and mortality. In many institutions including that of ours, most of the investigations are getting already completed by our surgical colleagues before sending the patient for PAC and risk stratification. For preoperative anaesthesia fitness, often a battery of investigations is being advised by residents of different surgical sub-specialties as also by the residents of anaesthesiology. According to American Society of Anesthesiologists (ASA) guideline, no routine laboratory or diagnostic screening test is necessary for preanaesthetic evaluation of patient. 8 The preoperative investigations should be based exclusively on the impression achieved from history, findings of physical examination, perioperative risk assessment and clinical judgment. ${ }^{9}$

In this present study, it was aimed to assess the perception and knowledge of residents on anaesthetic fitness. A questionnaire had been formulated to evaluate the domains of knowledge on preoperative investigations, preoperative assessment and risk stratification and general guideline for continuation of medications due to coexisting diseases as well as fluid therapy during fasting condition. It is observed that about $1-9 \%$ of residents relied on investigations based on history and physical examination as reflected through the answers of question no. 1 and 2. Unfortunately, most of the residents (71 - 93\%) had favoured routine investigations. This is not consistent with current recommendations, which advise prescribing investigations only after relevant history and physical examination findings. ${ }^{3,9}$ Only $38 \%$ and $21 \%$ of all residents had idea to assess the functional status first and then to advice for necessary investigations accordingly as per the findings of history, physical examination including the functional status in patients with co-morbid conditions such as hypertension, COPD, etc. (Question No. 3 and 4, in Annexure 1).

About 75 - 90\% house-staffs and PGTs responded favourably during selection of tools for risk assessment in presence of RTI, overall risk stratification and fasting guideline in elective surgery, while only about $60 \%$ interns did so in that field. (Question no. 5, 6 and 7 in Annexure 1) This may indicate the impact of cumulative clinical experience and maturity of judgment.

This is in contrast to better response of interns against question 3 assessing the knowledge, where they scored a bit better. This may be considered as an incidental finding.

Regarding general guideline of preoperative medication for coexisting diseases and fluid therapy during fasting condition (as assessed by question no. 8, 9 and 10 ), about $90 \%$, $33 \%$ and $88 \%$ of all residents choose valid responses respectively. A large number of residents (approximately $20 \%$ ) did not select any of the four options against question no. 9, which may be attributed from lack of experience.

Thus, it is observed that most of the residents (71\%) choose the option to advise routine preoperative investigations at the time of or prior to preanaesthetic checkup. Residents' existing knowledge on anaesthetic fitness demands further improvement.

Tsen LC and Colleagues ${ }^{10}$ observed in a survey that residents lack contact with either a preoperative clinic or with established curriculum in preoperative assessment. They also observed the scarcity of staff with enthusiasm and expertise in this arena. The authors emphasised about development of curriculums regarding establishment of preoperative clinics with proper preoperative assessment, patient management and conducting research on perioperative outcomes for several reasons. ${ }^{10}$ Improved physical diagnostic abilities and operative risk assessment skills could potentially enhance the patient outcomes and reduce the related costs. ${ }^{11}$ Interventions such as physical examinations and face-to-face discussions sufficiently before anaesthesia and surgery have been suggested to improve the anaesthesiologist-patient relationship, overall patient satisfaction and outcome. ${ }^{12}$ The time invested in preoperative evaluation yields an improved relationship between patient and anaesthesiologists. ${ }^{13}$

By effectively managing the resources involved in a preoperative clinic, anaesthesiologists enhance their roles within their institutions ${ }^{6}$ and may become involved with a greater portion of perioperative care resources. A greater satisfaction could be realized by developing an interest in preoperative care, patient management responsibilities, enhancing departmental and hospital support and creating beneficial patient outcomes. The authors also mentioned that if communication skills are addressed during residency training, they would be able to improve their ability to interact 
with patients and other healthcare providers in a better way, especially in future uncomfortable situations if such arises.

The findings of the present survey indicate about some lack of proficiency, which may reflect inadequacies in the course content or methodology of teaching which may demand educational interventions for modification in residents' perception and knowledge on anaesthetic fitness. The essence of 'ASA Practice advisory for preanaesthesia evaluation' should preferably be presented in a comprehensive manner. It should be circulated among the residents in the form of leaflet or handout. A short orientation program has to be repeated at 3 - 6 months' interval to change the practice and should be scrutinised and evaluated at intervals for any improvement achieved and maintained. Literature support that knowledge and skills gradually wane after learning something, especially when the knowledge is not integrated into regular practice. ${ }^{14,15}$ A knowledge-practice gap may be created by prescribing a battery of preoperative tests from the fear of litigation.

There are a few limitations in the present study. First, the study was done with only 76 residents. More residents from different disciplines and involving other institutions of the state catering services under the same curriculum would have revealed more valid and reproducible observations. Utilisation of electronically controlled survey system would have been better than our paper-based questionnaire survey, which has produced a limited output. Second, convenience sampling was adopted and hence it may raise questions of bias. ${ }^{16}$ It is difficult to ascertain whether our analysis results in either overestimation or underestimation of residents' knowledge as we have not performed a random sampling of a broader group of residents. Hence, it is also difficult to emphasise whether these findings are specific to only this group or can be generalised. Third, the questionnaires were evaluated for content validity, but the coefficient of validity was not calculated. However, there are positive points of this whatsoever small survey in the fact that there was $100 \%$ response beyond our expectation. The participants returned with their response with enthusiasm. No incentive or token of appreciation was offered to the participants for completion of the survey questionnaire.

\section{CONCLUSION}

Cost-effective healthcare delivery has great relevancy in developing countries. One of the major contributions in draining health care cost is inappropriate utilisation of medical technology and unnecessary investigations. Residents should be more rational in ordering pre-operative investigations. In the context of anaesthetic fitness, further enrichment of residents' knowledge is desired. This may be accomplished through educational interventions, which may help in reduction of operating room delay and cancellation, increased patient satisfaction and proper utilisation of existing resources.

\section{Annexure 1: Questionnaires and Information Data Sheet for Residents}

Name: Age: Qualification/Profession: Date:

\begin{tabular}{|c|c|c|}
\hline Sl. & Question with Options for Answer & Keys \\
\hline 1 & $\begin{array}{l}\text { What are the investigations you advice for PAC fitness? (A) Not specific, referred to anaesthesiologist for advising } \\
\text { the investigations, (B) Prescribe a battery of investigations as per our Dept./seniors protocol, (C) Put up without } \\
\text { investigations, (D) Specific investigation should be based on history, physical examination }\end{array}$ & $\mathrm{D}$ \\
\hline 2 & $\begin{array}{l}\text { What is your idea about minimal investigation for GA fitness for a patient having no co-morbid condition, (A) } \\
\text { Routine blood, S/U/C, LFT, CXR, ECG, BT \& CT, ECHO, (B) Pregnancy test for child-bearing female, Hb\% if pallor, } \\
\text { (C) No idea. }\end{array}$ & $\mathrm{B}$ \\
\hline 3 & $\begin{array}{l}\text { In a hypertensive patient what are the specific investigations you order? (A) CXR, ECG, ECHO, etc., (B) Functional } \\
\text { assessment, if not satisfactory then investigation. }\end{array}$ & $\mathrm{B}$ \\
\hline 4 & $\begin{array}{l}\text { In a patient with COPD what are the specific investigations you order? (A) CXR, ECG, PFT, etc. (B) Functional } \\
\text { assessment, if not satisfactory then investigation. }\end{array}$ & $\mathrm{B}$ \\
\hline 5 & $\begin{array}{l}\text { In a child with ARTI how will you put up with the patient? } \\
\text { (A) Put up with antibiotic, (B) Put up just after completion of antibiotic, (C) About } 4 \text { weeks after antibiotic } \\
\text { treatment. }\end{array}$ & $\mathrm{C}$ \\
\hline 6 & $\begin{array}{l}\text { For risk stratification to what you rely most? (A) On documented abnormal investigations, (B) Abnormal findings } \\
\text { in history and examination, (C) Both, (D) Every case is a high-risk case. }\end{array}$ & $\mathrm{C}$ \\
\hline 7 & Do you think fasting is essential for any elective surgery? (A) Yes, (B) No, (C) No idea & A \\
\hline 8 & $\begin{array}{l}\text { In a patient of Hypertension, Hypothyroidism, what is your idea about continuing the drug in the morning of } \\
\text { surgery for these co-morbid conditions? (A) Should be continued, (B) Should not be continued (C) No idea. }\end{array}$ & A \\
\hline 9 & $\begin{array}{l}\text { A patient with CAD posted for non-cardiac surgery will continue - (A) Nitrates, (B) Anti-arrhythmic drugs, (C) } \\
\text { Both, (D) None }\end{array}$ & $\mathrm{C}$ \\
\hline 10 & Do you think intravenous fluid is beneficial during preoperative fasting? (A)Yes (B) No (C) No idea. & A \\
\hline \multicolumn{3}{|c|}{$\begin{array}{l}\text { S/U/C, Blood for Sugar, Urea and Creatinine; LFT, Liver Function Tests; CXR, Chest X-Ray; ECG, Electrocardiogram, } \\
\text { BT \& CT, Bleeding Time and Clotting Time; Echo, Echocardiography; PFT, Pulmonary Function Test; } \\
\text { ARTI, Acute Respiratory Tract Infection; COPD, Chronic Obstructive Pulmonary Diseases }\end{array}$} \\
\hline
\end{tabular}




\section{REFERENCES}

1. Deutschman CS, Traber KB. Evolution of anesthesiology. Anesthesiology 1996;85(1):1-3.

2. Greene NM. The 31st rovenstine lecture. The changing horizons in anesthesiology. Anesthesiology 1993;79(1):164-70.

3. Apfelbaum JL, Connis RT, Nickinovich DG, et al. Practice advisory for preanesthesia evaluation: an updated report by the American society of anesthesiologists task force on preanesthesia evaluation. Anesthesiology 2012;116(3):522-38.

4. Pollard JB, Zboray AL, Mazze R. Economic benefit attributed to opening a perioperative evaluation clinic for outpatients. Anesth Analg 1996;83(2):407-10.

5. Fisher SP. Development and effectiveness of an anesthesia preoperative evaluation clinic in a teaching hospital. Anesthesiology 1996;85(1):196-206.

6. Alpert CC, Conroy JM, Roy RC. Anesthesia and perioperative medicine: a department of anesthesiology changes its name. Anesthesiology 1996;84(3):712-5.

7. National collaborating centre for acute care (UK) Preoperative tests: the use of routine preoperative tests for elective surgery-evidence, methods and guidance. London: national institute of clinical excellence 2003. Available from: https://www.nice.org.uk/guidance/cg3. [Last accessed on 2016, Oct 24].

8. American society of anesthesiologists. Statement on routine preoperative laboratory and diagnostic screening 2003. Available from: http://www.asahq.org/qualityand-practice-management/standards-and-guidelines. [Last cited on 2015 Nov 19].
9. Feely MA, Collins CS, Daniels PR, et al. Preoperative testing before noncardiac surgery: guidelines and recommendations. Am Fam Physician 2013;87(6):414-8.

10. Tsen LC, Segal S, Pothier M, et al. Survey of residency training in preoperative evaluation. Anesthesiology 2000;93(4):1134-7.

11. McAlister FA, Straus SE, Sackett DL. Why we need large, simple studies of the clinical examination: the problem and the proposed solution. CARE-COAD1 group. Clinical assessment of the reliability of the examination-chronic obstructive airways disease group. Lancet 1999;354(9191):1721-4.

12. Smith AF, Shelly MP. Communication skills for anaesthesiologists. Can J Anesth 1999;46(11):1082-8.

13. Kim JH. Preoperative evaluation of a surgical patient; preanesthetic interview by anaesthesiology residents. Korean J Anesthesiol 2012;62(3):207-8.

14. Thienthong S, Seehanoo J, Sriraj W, et al. The third year anaesthesiology residents knowledge regarding pediatric postoperative pain management. Open Journal of Anesthesiology 2013;3(9):388-92.

15. Manworren RC. Development and testing of the pediatric nurses knowledge and attitudes survey regarding pain. Pediatric Nursing 2001;27(2):151-8.

16. Saroyan JM, Schechter WS, Tresgallo ME, et al. Assessing resident knowledge of acute pain management in hospitalized children: a pilot study. J Pain Symptom Manage 2008;36(6):628-38. 